\title{
Development of the FEM wheel-soil model for the design of flexible pavements
}

\author{
Luboš Daniel ${ }^{1}$, Ján Kortiš ${ }^{1}$, Martin Decký $^{2, *}$, Peter Pisca ${ }^{3}$, and Peter Fabo ${ }^{1}$ \\ ${ }^{1}$ Research Centre, University of Zilina, Univerzitná 8215, 01026 Žilina, Slovakia \\ ${ }^{2}$ Faculty of Civil Engineering, Department of Highway Engineering, University of Zilina, Univerzitná \\ 8215, 01026 Žilina, Slovakia \\ ${ }^{3}$ Faculty of Civil Engineering, Department of Geodesy, University of Zilina, Univerzitná 8215, 010 \\ 26 Žilina, Slovakia
}

\begin{abstract}
The development of numerical models to simulate vehicle-road interaction problems is an important part of research into the design of roads. Current state of numerical tyre models, tyre-road contact algorithms and non-linear plastic soil material models have reached such a level that they could be difficult for practical civil engineers. The aim of the article is to design the spatial model of the wheel-road model using the FEM commercial software ADINA so that it can be used in practical road design too. The idea to create a rubber part of a tyre model as a combination of two layers of shell elements made of elastic materials is the most interesting. Contact wheel-road was modelled by the Constraint Function algorithm, which is part of the ADINA system. The first part of the article describes the model and experimental verification. In the second part there is a practical demonstration of application.
\end{abstract}

\section{Introduction}

The most widely used approaches considered to be reliable for calculation and assessment of stress and deformation state of road structure layers induced by traffic load are defined by standards. They often contains a few simplifications to be useful for practical purposes. The methodology, used in the Slovak Republic, is proposed by the Ministry of Transport and Construction of the Slovak Republic summarized in the Technical Conditions of Design of non-rigid and semi-rigid roads labelled TP 3/2009. In this case, the simplification includes replacement of the real load of the road by the wheels with loads on circular areas into which the axle force $2 \mathrm{P}=10 \mathrm{t}(11.5 \mathrm{t})$ are decomposed. The circular areas on which the pressure is decomposed have a radius of $115.2 \mathrm{~mm}(118.7 \mathrm{~mm})$ at a transverse distance $\mathrm{d}=$ $344 \mathrm{~mm}$ (Figure 1). Technical standard TP 3/2009 recommends layer thicknesses and elastic material properties of each layer directly that can be used in road design. The layered half-space model can be solved by various methods. The stress and deformation state of the layered half-space (Figure 1) can be solved as a solution of partial differential equations through integration transformations (e. g. Hankel transformation). This approach

\footnotetext{
* Corresponding author: martin.decky@svf.uniza.sk
} 
was used by authors Novotny and Hanuška [1] in the past and the LAYMED TS 0502 software is based on it. Another option is to solve a task in numerical ways, for example, using the Finite Element Method [2]. Several authors use FEM in the form of commercial software such as Plaxis [3, 4], ANSYS [5], ADINA [6], etc. to analyze these types of model.
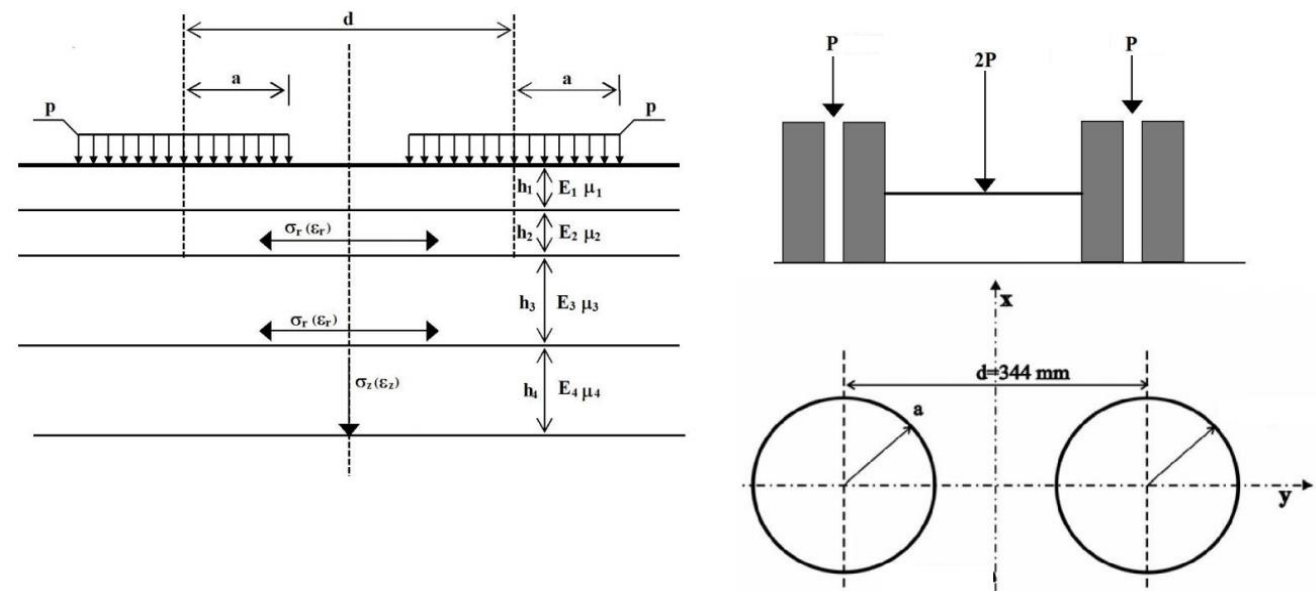

Fig. 1. Construction model of road and idealization of load from vehicle via

The article deals with the analysis of the spatial contact FEM model of the wheel-pavement system. Spatial numerical tyre models are important for mechanical engineers, for example, when special tyre structures are designed [7] or they are used for realistic vehicle models to analyse their dynamic behaviour [8]. FEM model simulates real hyper-elastic behaviour of cord-rubber by using a combination of several types of elements (shell, beam and 3D solid elements) and by using special hyper-elastic and nonlinear material models based on Mooney-Rivlin [9], Ogden or Neo-Hookean material models [10]. The problem of these analyses is to obtain realistic input material properties. The experimental measurements and model updating techniques are recommended for this purpose [10].

The article is interesting in designing of the simplified spaced tyre model by using a combination of two layers of shell elements with linear elastic material properties. The numerical model is experimentally verified by a simple pressure test to analyse how the vertical spring stiffness differs if the value of tyre pressure changes.

\section{Development of the FEM model of the tyre}

The numerical tyre model based on the real tyre KAMA 11.00 R20 used as a common tyre for the heavy trucks. The surface of the model was acquired with 3D scanning technology, using the device Leica C10 from the ScanStation Scanner class. The processed and cleared point cloud obtained from the scan is shown in Figure 2a. Geometry of the cross section (Figure 2.b) was, in the next step, exported to the CAD system which was used to model spatial model of the tyre (Figure 2.c). This geometry was used to create the model in the FEM system ADINA (Figure 2.d). 


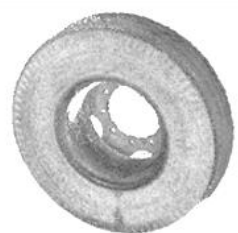

a.)

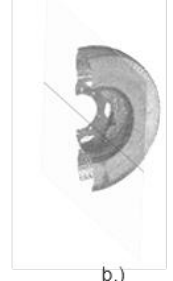

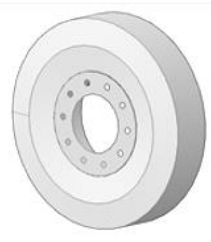

c.)

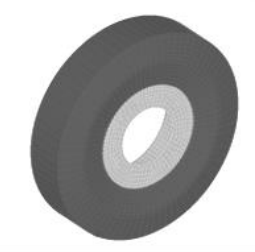

d.)

Fig. 2. Models of truck wheel a.) Scan of geometry b.) Cut of scan point cloud c.) CAD model d.) FEM model

The tyre model consists of two main parts, i.e. steel disc and a cord-rubber tyre. The steel disc is created from shell elements with a thickness $7 \mathrm{~mm}$ for which a linear elastic material $(\mathrm{E}=210000 \mathrm{MPa}, \mathrm{v}=0.3$ (steel)) is used. The steel part acts as a rigid element so its importance lies especially in the distribution of the axle-to-tyre load. The rubber part of the tyre is created from shell elements with a thickness $50 \mathrm{~mm}$ where a linear elastic material is also used with the parameters $(\mathrm{E}=1.381 \mathrm{MPa}, \mathrm{v}=0.49$ (rubber)). The tyre is reinforced with a thin steel shell element of $0.1 \mathrm{~mm}$ thickness to achieve suitable tyre deformation properties at tensile and bending stress (Figure 3).

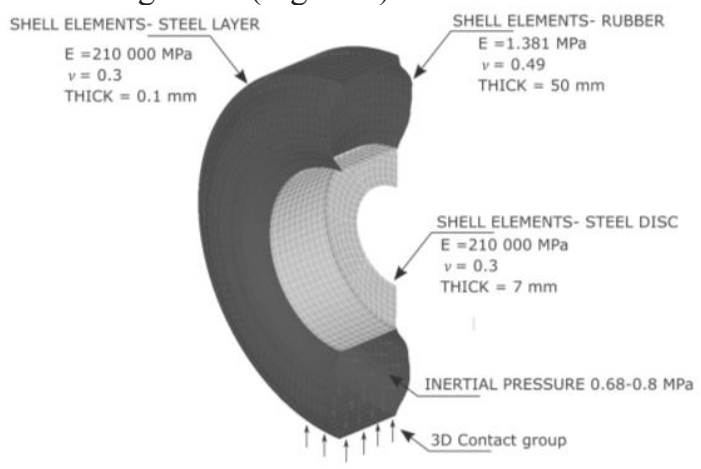

Fig. 3. Description of FEM wheel's model

The internal tyre pressure is created as a load state on the inner wall of the tyre, with an intensity of pressure $0.68 \mathrm{MPa}$ or $0.8 \mathrm{MPa}$. This load is initialized at the beginning of the simulation, even before the contact is initialized. The contact surface is defined on the upper surface of the tyre. For the 3D contact algorithm, in the system ADINA, a Constraint Function with a Coulomb friction coefficient of 0.7 is used.

\section{Experimental verification of the FEM wheel model}

The behaviour of the numerical model under vertical pressure was verified by an in situ experimental test. The experiment was situated on the testing stand of the Civil Engineering Faculty of the University of Žilina. Vertical deformation of the tyre was measured as a response to the force applied on the wheel through circular steel plate placed on top of it (Figure 4b). Two variants with an internal tyre pressure of $0.8 \mathrm{MPa}$ and $0.68 \mathrm{MPa}$ were tested. 


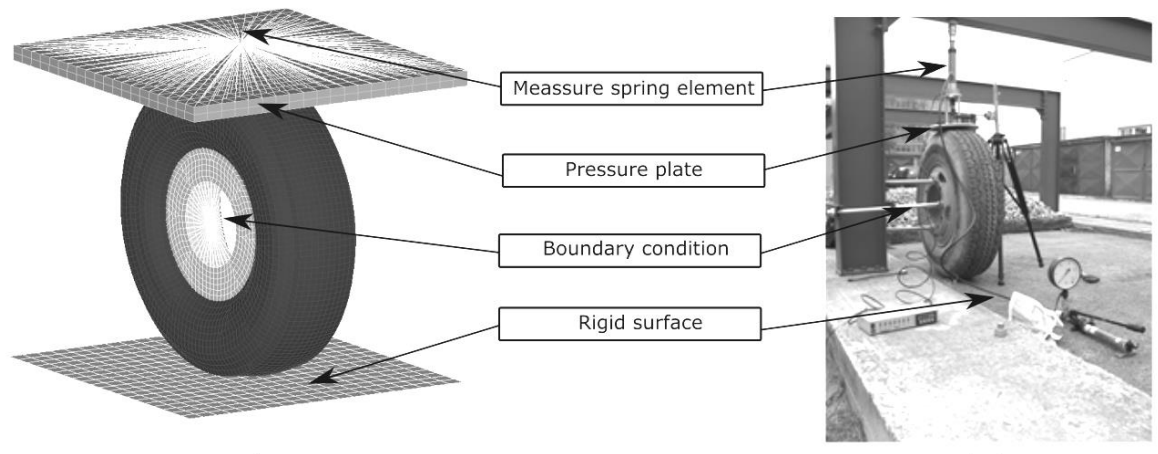

a.)

b.)

Fig. 4. Description of models a.) FEM model - ADINA, b.) Experimental model

Verification of the numerical model of the tyre was done by simulating the same boundary conditions as for experimental pressure test were defined. The loading of the model is shown and compared with the experiment in Figure 4. The element for measurement of the pressure force in the model is a linear spring on the top of loading plate. The bottom point of the spring is connected to the pressure plate by rigid links and the top point is vertically shifted, representing the pressure load of the model. The boundary conditions on the steel disc allow only a vertical displacement. The comparison of the results obtained from experiments and simulations are shown in Figure 5. The graphs represent the relationship between the tyre's vertical displacement and the pressure force.

a.)

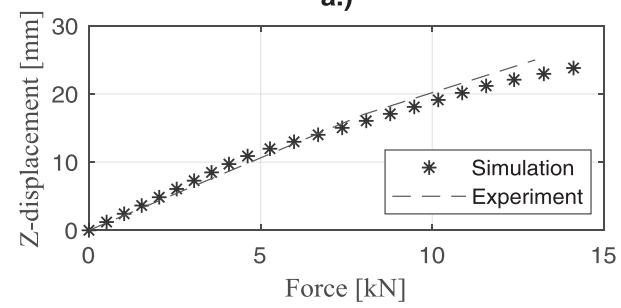

b.)

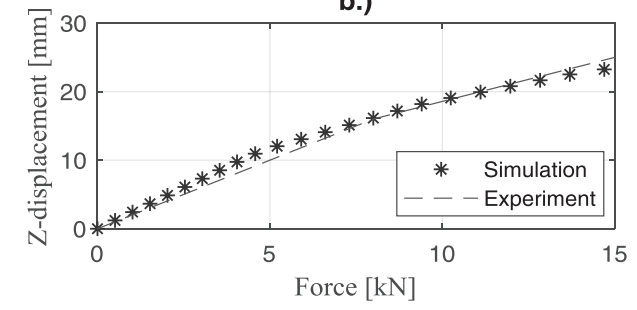

Fig. 5. Results of comparison model vs experimental tests a.) Pressure $0.8 \mathrm{MPa}$ b.) Pressure 0.68 $\mathrm{MPa}$

The results show a good match between simulations and experiments. The stiffness of the model is defined by similar curve as which was obtained from the experiment. Because of this, it can be proposed to use the model proposed for other related applications.

\section{Application of the FEM wheel-soil model}

The presented wheel model was used to assess the load capacity of pavement layers. The task of the assessment was to analyse the local behaviour of the flexible pavement under a static load using a 3D tyre-soil model. The analysed variables were vertical normal stress (Figure 6) and vertical displacements of individual layers (Figure 7). Linear elastic materials have been used to define mechanical characteristics of the pavement layers. 


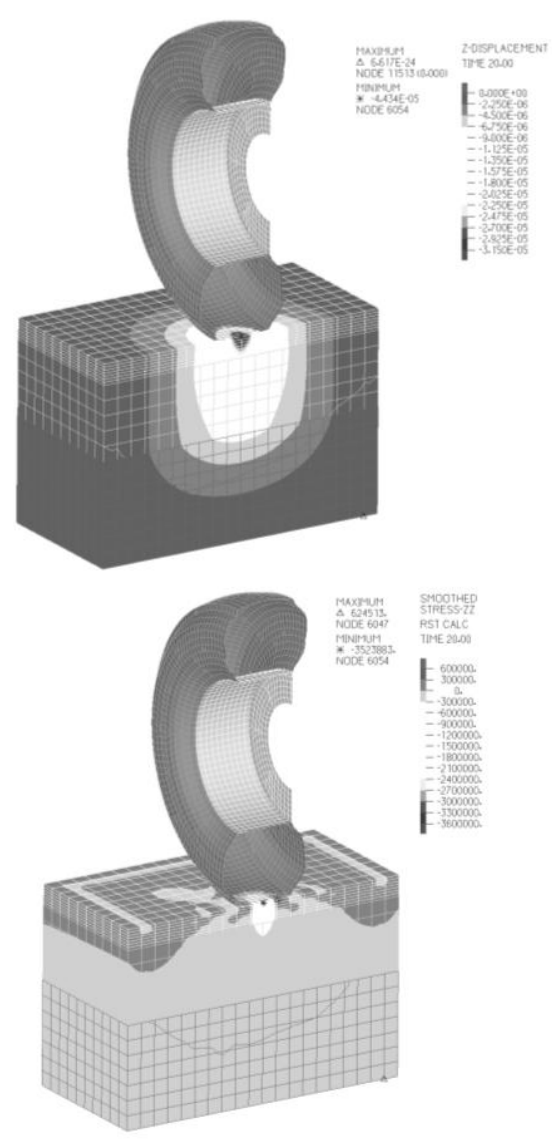

Fig. 6. Normal stress $-\mathrm{ZZ}$

Fig. 7. Z-displacement in soil layers

Table 1. The structure of the pavement

\begin{tabular}{|c|c|c|c|}
\hline $\begin{array}{c}\text { Pavement's } \\
\text { layer }\end{array}$ & $\begin{array}{c}\text { Thickness } \\
{[\mathrm{mm}]}\end{array}$ & $\begin{array}{c}\text { Young } \\
\text { modulus } \\
{[\mathrm{MPa}]}\end{array}$ & $\begin{array}{c}\text { Poisson } \\
\text { number [-] }\end{array}$ \\
\hline $\begin{array}{c}\text { Asphalt } \\
\text { concrete }\end{array}$ & 70 & 6000 & 0.3 \\
\hline $\begin{array}{c}\text { Asphalt- } \\
\text { coated } \\
\text { aggregate }\end{array}$ & 250 & 4600 & 0.33 \\
\hline Gravel & 350 & 2500 & 0.3 \\
\hline
\end{tabular}

The pavement structure is common and widely used in the Slovak Republic. The proposed material parameters are described in Table 1. The obtained results verified the load capacity of the pavement and can be used in the design of the reconstruction or planned extension of the airport runway. 


\section{Conclusions}

The article presents an approach how to calculate the static interaction problem in the system tyre-soil. The proposed spatial model was created in the commercial ADINA system and was experimentally verified. An example of practical application is also presented to show a possibility to use the proposed model of the wheel. The methodology can be recommended for design and assessing of some special types of flexible roads. The next of research is to apply a spatial wheel model as a loading of pavement models where plastic material models are defined for structural layers. There is also tendency to investigate a behavior of the model under a dynamic conditions such as braking, impact or acceleration.

This paper was supported by the Grant Research Cetnre of The University of Zilina - Second Phase (grant No. 313011D011)

\section{References}

1. B. Novotný, A. Hanuška, Teória vrstevnatého polpriestoru (VEDA publishers SAV, Bratislava, 1983)

2. K. J. Bathe, Finite element procedures (2006)

3. C. Rabaiotti, Pavement service life prediction and inverse analysis with PLAXIS 3D (PLAXIS Bulletin, 2015)

4. S. A. Khan, S. M. Abbas, Numerical modelling of highway embankment by different ground improvement techniques (IJIRAE, 2014)

5. A. H. Abed, A. A. Al-Azzawi, American Journal of Engineering and Applied Sciences (2012)

6. M. Novak, B. Birgisson, R. Roque, Near-surface stress states in flexible pavements using measured radial tyre contact stresses and ADINA (Computers \& structures, 2003)

7. H. Holscher, et al., Modeling of pneumatic tyres by a finite element model for the development a tyre friction remote sensor (CAESAR, Ludwig-Erhard-Allee, 2004)

8. M. Shiraishi, et al., Proceedings of the 6th International LS-Dyna Users conference, EPL (2008)

9. M. Mooney, Journal of applied physics (1940)

10. J. M. Conradie, P. S Els, P. S. Heyns, Proceedings of the Institution of Mechanical Engineers, Part D: Journal of Automobile Engineering (2016) 